\title{
COVID-19 Pandemisi Sürecinde Sağlık Okuryazarlığının Önemi
}

\author{
The Importance of Health Literacy During COVID-19 Pandemic
}

\author{
Özgecan Gül Hızal'
}

\section{Öz}

31 Aralık 2019'da Dünya Sağlık Örgütü (DSÖ) Çin Ülke Ofisi, Çin'in Wuhan şehrinde etiyolojisi bilinmeyen pnömoni vakalarını bildirmiş, 7 Ocak 2020'de etken daha önce insanlarda tespit edilmemiş yeni bir koronavirüs (2019- nCoV) olarak tanımlanmıştır. Dünya Sağlık Örgütü COVID-19 salgınını 30 Ocak'ta "uluslararası boyutta halk sağlığı acil durumu" olarak sınıflandırmış, ilk salgının başladığı Çin dışında 113 ülkede COVID-19 vakalarııı görülmesi, virüsün yayılımı ve şiddeti nedeniyle 11 Mart'ta küresel salgın (pandemi) olarak tanımlamışıı. COVID-19 hastalığının hızıı bir şekilde pandemiye dönüşmesi, insanları bu virüs hakkında bilgi edinme, uygulama ve hızlı bir davranış değişikliğine zorlamıştır. Pandemi sürecinde çeşitli platformlarda COVID-19 ile ilgili bilgiler paylaşılmaya başlanmıştır. Bu bilgilerde yer alan tıbbi terimler, maske kullanımı ve sosyal mesafe gibi önlemlerin çoğuyla daha önce karşılaşmamış olan toplumda kaygı ve endişe artmış, sosyal platformlarda yanlış bilgilerin yayılması hızlanmıştır. Bu dönemde sağlık okuryazarlığının önemi artmış ve birçok araştırma yapılmıştır. Bu çalışmada konu ile ilgili güncel literatürler incelenmiş olup konunun önemine dikkat çekmek amaçlanmıştır.

Anahtar Kelimeler: Sağılk Okuryazarlığı, COVID-19 Pandemisi, İnfodemik. 


\begin{abstract}
On 31 December 2019, the World Health Organization China Country Office was informed of cases of pneumonia unknown etiology (unknown cause) detected in Wuhan, China and on 7 January 2020, the agent was identified as a new coronavirus (2019-nCoV) that was not previously detected in humans. The WHO classified the COVID-19 outbreak as an "international public health emergency" on 30 January 2020, with the occurrence of COVID-19 cases in 113 countries except China, where the first outbreak started, was defined as a global epidemic (pandemic) on March 11 due to the spread and severity of the virus. The rapid transformation of COVID-19 disease into a pandemic has forced people to learn about this virus, practice it, and make a rapid change of behavior in their lives. During this process, information about COVID-19 began to be shared on various platforms and apprehension and anxiety have increased in society, which has not encountered most measures such as medical terms, use of masks and social distance contained in shared information, and the spread of misinformation on social platforms has accelerated. During this period, the importance of health literacy has increased and many studies were conducted. In this study, current literature on the subject was examined and it was aimed to draw attention to the importance of the health literacy.
\end{abstract}

Keywords: Health Literacy, COVID-19 Pandemic, İnfodemic.

\title{
Giriş
}

SağlıkOkuryazarlığı, bireylerin sağlıklarıylailgilidoğru kararlar alabilmesi için, sağlık ve sağlık hizmetleriyle ilgili bilgiye ulaşmaları, bu bilgiyi anlama, değerlendirme ve uygulayabilme ile ilgili yeterlilikleri olarak tanımlanır (1). Dünya Sağlık Örgütü sağlık okuryazarlığını bireylerin iyi sağlık halinin sürdürülmesi ve geliştirilmesi amacıyla sağlıkla ilgili bilgiye ulaşması; bu bilgiyi anlaması ve kullanması için gerekli olan bilişsel ve sosyal beceri kapasitesi olarak tanımlar (2). Günümüzde insanların hastalıklarını bilmesi, hastalığa ilişkin bulgularını belirleyebilmesi ve kendileri için iyi olduğuna inandıkları kararları verebilmesi beklenmektedir. Sağlık okuryazarlığı yaşam kalitesini ve yaşam süresini arttırdığı gibi sağlık eşitsizliklerinin giderilmesine de katkı sağlar (3). Yetersiz sağlık okuryazarlığı düzeyi sağlıksız yaşam, kronik hastalıklarla ilgili bilgi eksikliği, yapılan açıklamaları ve tedaviyi anlamada zorluk, tedavi uyumsuzluğu, yanlış/gereksiz ilaç kullanımı, hastaneye yatış oranı ve sağlık maliyetlerini arttırma gibi birçok olumsuzluğa neden olur (4).

Sağlık okuryazarlığı hayatın her alanında olduğu gibi afet, salgın gibi toplum tarafından daha önce karşılaşılmamış olağanüstü dönemlerde de büyük önem taşımaktadır. Aralarında Avrupa'nın da yer aldığı dünyanın gelişmiş ülkelerinde dahi yetersiz sağlık okuryazarlığı bir halk sağlığı sorunu olarak öne çıkmaktadır $(5,6)$. Hiç kimsenin her zaman tam olarak sağlık okuryazarı olmadığı ve güçlü eğitim sistemine sahip ekonomik olarak gelişmiş ülkelerde bile, herkesin bir noktada önemli sağlık bilgilerini anlama, bunlara göre hareket etme veya karmaşık bir sistemi yönetmede yardıma intiyacı olduğu bilinmektedir (7). 


\section{Pandemi ve Sağlık Okuryazarlığı}

31 Aralık 2019'da Dünya Sağlık Örgütü (DSÖ) Çin Ülke Ofisi, Çin'in Hubei eyaletinin Wuhan şehrinde etiyolojisi bilinmeyen pnömoni vakalarını bildirmiştir. 7 Ocak 2020'de etken daha önce insanlarda tespit edilmemiş yeni bir koronavirüs (2019-nCoV) olarak tanımlanmıştır. Salgının başladığı Çin dışında 113 ülkede COVID-19 vakalarının görülmesi, virüsün yayılımı ve şiddeti nedeniyle 11 Mart’ta küresel salgın (pandemi) olarak tanımlamıştır (8).

COVID-19 hastalığının hızlı bir şekilde pandemiye dönüşmesi, insanları bu virüs hakkında bilgi edinme, edindikleri bilgileri uygulama ve hızı bir davranış değişikliği oluşturmaya zorlamıştır. Dünya çapında çeşitli platformlarda COVID-19 ile ilgili bilgiler hızla artmış, COVID-19 enfeksiyonun yayılımı ve önlenmesi gibi konularda eğitim vermeyi amaçlayan sağlık iletişimi yaygınlaşmıştır. Bu süreçte dünyada hem bir pandemi hem de bir infodemi yaşanmıştır $(9,10)$. İnfodemi, internette veya diğer iletişim teknolojileri yoluyla büyük miktarda bilginin hızla yayılması anlamına gelen bilgi salgınının kısaltması olarak tanımlanmaktadır (11). "Infodemi” ilk olarak 2003 yılındaki SARS salgını sırasında ortaya çıkan bir kavram olmasına rağmen 2020'ye kadar literatürlerde pek kullanılmamıştır (12). Mevcut pandemi sürecinde, olumsuz bilgi önyargısı felaket düşüncesine neden olurken olumlu bilgi önyargısı da gerçekçi olmayan iyimserliğe neden olur. Bu durum infodemik anlamda risklerin ortaya çıkmasına sebep olur. Bu riskler sürecin yönetimini zorlaştırmaktadır (13). Toplumdaki sınırlı ve yetersiz sağlık okuryazarlığı da sessiz bir salgın olarak değerlendirilmektedir (14).

Sağlık kurumlarının sağlık okuryazarlığı ile ilgili ilkeleri dikkate alması, anlaşılabilir ve uygulanabilir bilgi paylaşması, herkes tarafından erişilebilir bilgi kaynakları oluşturması salgının seyrini belirleyen önemli faktörler arasında yer alacaktır. Bu süreçte mücadele edilmesi gereken bir başka konu da yanlış bilgi paylaşımıdır. Yanlış haberler toplumda korkunun yayılmasına neden olabilir. Koronavirüs salgını sırasında özellikle yalan haberlerin ya da doğrulanmamış bilgilerin sosyal medya aracılığıyla virüsten daha hızlı yayıldığı belirtilmektedir $(2,14,15)$.

Dünyanın dört bir yanındaki ülkeler, virüsün bulaşmasını sınırlamak için yoğun çaba sarf etmektedir. İzolasyon, temas kısıtlamaları, seyahat yasakları gibi önlemler bireyler ve toplum üzerinde geniş kapsamlı olumsuz etkilere sebep olmakta ve daha önce karşılaşılmayan tıbbi terimlerin yoğun kullanımı sonucu kafa karışıklığına sebebiyet vermektedir $(16,17)$. COVID-19'un güvenilirliği ve etkinliği kanıtlanmış spesifik bir tedavisi henüz bulunmadığından salgının kontrol altına alınabilmesi için alınan tedbirlerin öneminin toplum tarafından doğru bir şekilde anlaşıması ve uygulanması gerekmektedir. Sağlık okuryazarlığı düzeyinin yüksek olması, salgın yönetimini kolaylaştıracaktır $(18,19)$. Sağlık okuryazarlığı, COVID-19 ile ilgili güvenilir bilgiler ile konudaki yanlış bilgiler arasında ayrım yapılmasını kolaylaştııı, sağlık bilgileri ve sağlık hizmetlerinin etkin kullanımına yardımcı olur, toplumu koronavirüs ve COVID-19 pandemisi sırasında bilinçli sağlık kararları alma, sağlıklı ve koruyucu davranışlar uygulama konusunda güçlendirir $(5,20,21)$. 


\section{Türkiye'de Sağlık Okuryazarlığı Düzeyi}

2017 yılında Türkiye'de ulusal düzeyde SOY düzeyi Sağlık Bakanlığı tarafından yürütülen bir çalışma ile ortaya konmuştur. TSOY-32 ölçeğinin kullanıldığı bu çalışma yüz yüze anket uygulaması yöntemi ile gerçekleştirilmiş ve araştırmaya 6.228 kişi dâhil edilmiştir. Araştırmada sağlık okuryazarlığı düzeyinin toplumun \%30,9'unda yetersiz, \%38,0'ında sorunlu-sınırlı, \%23,4'ünde yeterli, \%7,7'sinde ise mükemmel düzeyde olduğu sonucuna varımıştır. Araştırma sonucuna göre sağlık okuryazarlığı yetersiz olanlarla sorunlu-sınırlı olanların toplamının \%68,9 olduğu görülmektedir. Bu da ülkedeki her on kişinin yedisinin sağlık okuryazarlığı düzeyinin yetersiz olduğunu ve halk sağlığı açısından bir problem ile karşı karşıya olunduğu anlamına gelmektedir (22).

\section{Türkiye'de Pandemi Süreci ve Yönetimi}

Türkiye'de pandemi süreci Sağlık Bakanlığı'nın kurmuş olduğu Pandemi Bilim Kurulu koordinasyonu ile yönetilmektedir. Sağlık Bakanlığı, COVID- 19 tanı, tedavi ve izleme ile ilgili ilk rehber 24 Ocak 2020'de resmi internet sitesinde yayınlamıştır. Pandemi sürecinde kanıta dayalı bilgilerin artmasıyla rehber ve algoritmalar düzenli olarak güncellenmiştir. Bu rehberler ve güncellemeler sağılı hizmet sunucuları için, tanı, tedavi ve izlem konularında karşılaştıkları aşırı bilgi ile baş etmek açısından yararlı olmuştur (23).

Ülkemizde pandemi süresince virüsün yayılmasını yavaşlatmak ve sağlık sistemi üzerindeki baskıyı azaltmak için, belirli tarihlerde uygulanan sokağa çıkma yasakları, iller arası seyahat kısıtlamaları ve sosyal mesafe kurallarını kapsayan çeşitli düzenlemeler hayata geçirilmiştir. Daha önce karşılaşılmamış ve hızla artan tehdidi öğrenme ihtiyacı insanları elektronik kaynaklardan konuyla ilgili araştırma yapmaya sevk etmiştir. Özellikle sosyal medyadaki bilgi kirliliği ve yanlış yönlendirici tavsiyeler insanların yanlış uygulamalar benimseyerek toplum sağlığını olumsuz etkilemesi gibi sonuçlara neden olmuştur $(7,19)$. Bu yanlış bilgi akışını önlemek amacıyla COVID-19'a yönelik hazırlanan https://covid19. saglik.gov.tr sitesinde toplumun her kesimine yönelik bulaş, korunma, maske kullanımı, el yıkama gibi pek çok konuda bilgilendirmeler mevcuttur. Ayrıca sitede yer alan COVID-19 sözlüğünde bulaşma yolları, sosyal mesafe, entübasyon, izolasyon gibi kavramların anlaşılır tanımları yapıımış ve sıkça sorulan sorular -halka ve sağlık hizmet sunucularına yönelik olmak üzere iki farklı grupta- cevaplanmıştır. Bu bilgiler internet sitesinin yanı sıra Sağılı Bakanlığı'nın resmi sosyal medya hesaplarından da paylaşılmış, halkın birinci kaynaktan doğru bilgiye kolayca ulaşması amaçlanmıştır $(23,24)$. Milli Eğitim Bakanlığı da veli, öğretmen ve öğrenciler için bilgilendirme rehberi hazırlamış; öğrenciler için ek olarak okullarda uygulanması gereken COVID-19 tedbirleri konusunda farkındalık kazanması ve güvenli bir şekilde okula yeniden devamını sağlamak amacıyla için kamu spotları hazırlamıştır. Öğrencilerin COVID-19 riskinden korunmaları için okula gelirken ve okulda kaldıkları süre boyunca el yıkama, maske, sosyal mesafe, sınıfı havalandırma, temassız oyun oynama gibi temel önlemlere yer verilmiştir (25). 


\section{Pandemi Sürecinde Sağlık Okuryazarlığı ile ilgili Dünya Genelinde Yapılan Çalışmalar}

Almanya'da Orkan Okan ve arkadaşları tarafından yapılan bir çalışmada koronavirüs ile sağlık okuryazarlığı ilişkisini belirlemek için geliştirilmiş bir değerlendirme aracının uygulanabilirliğini test etmek, yetişkinlerin koronavirüs ile ilgili sağlık okuryazarlığını değerlendirmek, sağlık okuryazarlığındaki farklılıkların sosyodemografik özellikler ile ilişkisini incelemek ve katılımcıların COVID-19 infodemisi sırasında paylaşılan sağlık bilgileri hakkındaki düşüncelerini incelemek amaçlanmıştır. Bu amaçla Bielefeld Üniversitesi ve Allensbach Enstitüsü işbirliğiyle 31 Mart-7 Nisan 2020 tarihleri arasında Almanya'daki yetişkin internet kullanıcılarına ( $\geq 16$ yaş) kesitsel çevrimiçi anket uygulanmış, çalışmaya 1.037 kişi dâhil edilmiştir. Katılımcılara genel olarak koronavirüs hakkında ne kadar bilgilendirildikleri, bu dönemde paylaşılan bilgilerin kafa karışıklığına sebebiyet verip vermediği gibi sorular yöneltilmiştir. Verilen cevaplar, Avrupa Sağlık Okuryazarlığı Anketine (HLS-EU-Q) göre değerlendirilmiştir. Araştırma sonucunda sağlık okuryazarlığı düzeyinin katılımcıların \%15,2'sinde yetersiz, \%34,9'unda sorunlu ve \%49,9'unda yeterli düzeyde olduğu tespit edilmiştir. Cinsiyet, yaş, eğitim, hane halkı geliri veya ikamet bölgesi ile önemli bir ilişki saptanmamıştır. Koronavirüs hakkında ne kadar bilgilendirildikleri sorusuna \%67'si çok iyi, \%46,7 iyi, \%19,1 yeterince iyi değil/iyi değil yanıtını vermiştir. Katılımcıların toplam \%56,7'si COVID-19 hakkındaki bilgi çeşitliliğinin kafa karıştırıcı olduğunu ifade etmiştir. Kadınların erkeklere göre; gençlerin de diğer gruptakilere göre daha fazla kafasının karıştığı sonucuna ulaşılmıştır. Çocukları 18 yaşından küçük olan yetişkinlerin de kafa karışıklığı diğer gruplardan daha yüksek bulunmuştur.

Bu çalışma, koronavirüs ile ilgili kapsamlı sağlık okuryazarlığı üzerine yapılan ilk toplum temelli araştırma olması ve COVID-19 infodemik bağlamında sağlık okuryazarlığını analiz etmesi açısından büyük önem taşımakta olup sonraki çalışmalara rehberlik edeceği düşünülmektedir. Bununla birlikte, katılımcıların önemli bir kısmının $(\% 50,1)$ ortalama sağlık okuryazarlığı seviyesinin altında olduğundan, koronavirüs ile ilgili toplumun sağlık okuryazarlığının arttıııması, yanlış bilgi kaynaklarının kullanımının önlenmesi, güvenilir bilgilere ulaşmak ve doğru kararlar vermek için halkın teşvik edilmesi gerektiği sonucuna ulaşılmıştır (16).

Norveç'te Kirsti Riiser ve arkadaşları tarafından da benzer bir çalışma yürütülmüştür. Bu çalışmada COVID-19 pandemisi sırasında Norveç'teki adolesanların sağlık okuryazarlığı düzeyi ve sağlığın korunması için aldıkları önlemlerini tanımlamak; sağlık okuryazarlığı ile virüsün yayılmasının önlenmesi için bilgi ve davranış arasındaki ilişkiyi araştırmak amaçlanmıştır. Bu kesitsel çalışmaya kartopu örneklemi ile seçilen 16-19 yaş arasındaki 2.205 Norveçli adolesan dâhil edilmiştir. Anket Nisan ayında, elektronik ortamda yapılmış olup 2,5 haftada tamamlanmıştır. Katılımcılara demografik bilgileri, pandemiyle ilgili koruyucu sağlık önlemleri hakkında yararlandıkları bilgi kaynakları, koronavirüs ile enfekte olup olmadıkları/şüpheleri sorulmuş ve güncel durumlarını (karantinada olup olmadıkları) belirtmeleri istenmiştir. Katılanların \%82,5'i kı, \%17,5'i erkek olup yaş ortalaması 17,3 olarak bulunmuştur. Katılımcıların \%0,5'i COVID-19 geçirmiş/hâlihazırda 
enfekte olup \%7,4'ü COVID-19 geçirdiği/hâlihazırda enfekte olduğundan şüphelendiğini bildirmiştir. Katılımcıların \%90,8'i sosyal kısıtlamalarla evde kalırken, \% 4,2'si izole olduğu/karantinaya alındığını belirmiştir. Erişilen sağlık bilgi kaynaklarının ortalama sayısı 6,1 olarak belirtilmiştir. TV $(\% 86)$ ve aile $(\% 81,1)$ pandemiyle ilgili sağlık bilgilerinin ana kaynakları olarak belirtilirken katılımcıların \%58,6'sı bilgi kaynağı olarak gazete okuduğunu da ifade etmiştir. Snapchat $(\% 59,8)$ ve Facebook $(\% 51,1)$ en sık kullanılan sosyal medya platformları olarak belirtilmiştir. Katılımcıların \%89,4'ü koruyucu önlemler ile ilgili sorulan açık uçlu soruya yanıt vermiş ve her biri ortalama 4,09 öneride bulunmuştur. Katılımcılar, koruyucu önlemler hakkında genel olarak iyi bilgilendirilmiş olup el yıkama, fiziksel mesafe ve sosyal ilişkilerde sınırlama en sık hatırlanan önerilerdir. Büyük bir çoğunluk, hem el yıkama hem de sosyal mesafeyle ilgili olarak koruyucu önlemlere ilişkin kılavuzlara uyduğunu bildirmiştir. Araştırma sonucunda katıımcıların sağlık okuryazarlığı düzeyi yüksek bulunmuş olup ve el yıkama bilgisi ve davranışının yanı sıra sosyal kısıtlamaların uygulanmasıyla istatistiksel olarak anlamlı ilişki tespit edilmiştir.

Bu çalışma, COVID-19 pandemisi sırasında ergenler arasında sağlık bilgi kaynaklarını ve bilgilerini, sağlık okuryazarlığını, sağlığı koruma önlemlerini ve sağlık okuryazarlığı düzeyini tanımlayan ilk çalışmalardan olması sebebiyle önem arz ermektedir. Katılımcıların sağlık okuryazarlığı seviyesinin yüksek olduğu ve sağlık yetkililerinin yönergelerini takip etme konusunda motive oldukları görülmüştür. Bilgi sahibi olmak için, ailelerini ve geleneksel medyayı sosyal medya platformlarından daha fazla bilgi kaynağı olarak kullanmaları araştırmacılar tarafından ilginç olarak yorumlanmıştır (26).

Son olarak Amerika Birleşik Devletleri'nde yaş ve komorbid koşullar nedeniyle enfeksiyona daha yatkın olan yetişkinlerin COVID-19 farkındalığı, bilgi, tutum ve davranışlarını belirlemek için benzer bir çalışma yapılmıştır. 13-20 Mart 2020 tarihleri arasında yapılan çalışmaya en az bir kronik hastalığı olan 23-88 yaş arasındaki 630 kişi dâhil edilmiştir. Katıımcılara koronavirüse yakalanma konusundaki endişe düzeyleri, COVID-19'un başlıca semptomları ve korunmak için alınması gereken önlemler, COVID-19 nedeniyle günlük rutinlerinde değişiklik yapıp yapmadıkları, kendilerinin veya tanıdıkları birinin koronavirüse yakalanma olasılığı gibi sorular yöneltilmiştir. Tüm katıımcılar COVID-19'u duymuş ve çoğu potansiyel tehdidin yüksek olduğunu düşünmektedir. COVID-19 tehdidi, 70 yaş ve üstü yetişkinler ile kadınlar tarafından daha ciddi olarak değerlendirilmiştir. Katılımcıların yaklaşık dörtte biri $(\% 24,6)$ koronavirüse yakalanma konusunda "çok endişeli" olduğunu ifade ederken \%12,9'u hiç endişe duymadığını belirtmiştir. Katıımcıların \%28,3'ü semptomları, \%30,2'si de enfeksiyonu önleme yollarını doğru bir şekilde tanımlayamamıştır. Her 4 yetişkinden biri (\%24.6) COVID-19 geçirme intimalinin "hiç olmadığını" düşünmekte birlikte \%9,5'i kesinlikle veya muhtemelen enfekte olacağını belirtmiştir. \%21,9'u COVID-19'un günlük rutinleri üzerinde çok az etkisi olduğunu veya hiç etkisi olmadığını bildirmiştir. Siyahi olan, yoksulluk seviyesinin altında yaşayan, yetersiz İngilizce seviyesine sahip ve sağlık okuryazarlığı düşük olan katıımcıların COVID-19 hakkında daha az endişelendiği, enfekte olacağına inanmadığı ve olası bir salgına hazırlıklı hissetmediği sonucuna ulaşılmıştır. COVID-19 tehdidini kadınlar erkeklerden; ekonomik geliri yüksek olan kişiler de düşük ekonomik gelire sahip olanlardan daha yüksek olarak değerlendirmiştir. Ayrıca komorbid koşullara sahip birçok yetişkinin COVID-19 hakkında kritik bilgiden yoksun oldukları ve endişelerine rağmen günlük rutinleri değiştirmedikleri sonucuna ulaşılmıştır (27). 


\section{Sonuç}

Günümüzde COVID-19'un güvenilirliği ve etkinliği kanıtlanmış spesifik bir tedavisi bulunmamakta olup aşı çalışmaları devam etmektedir. Salgının kontrol altına alınabilmesi için alınan tedbirlerin öneminin toplum tarafından doğru bir şekilde anlaşılması ve herkes tarafından uygulanması gerekmektedir. Yapılan çalışmalar sağlık eğitimi ve sağlık okuryazarlığının, COVID-19 pandemisinin yayılmasını yavaşlatılması ve COVID-19 infodemisinin toplum üzerindeki olumsuz etkilerinin azaltılmasında kritik öneme sahip olduğunu göstermiştir. Coronavirüs ve COVID-19 ile ilgili bilgi paylaşım sürecinde verilen mesajlar herkes tarafından anlaşıı olmalı, kolay erişebilmelidir. İnfodemik sürecinde önemli aktörlerden olan sosyal medya kullanıcıları sorumlu davranmaya, güvenilir sağlık bilgilerinin yayılmasını desteklemeye ve internet sitelerinde yanlış ve yanıltıcı bilgilerin yer almasını engellemeye teşvik edilmelidir.

\section{Kaynakça}

- Nutbeam, D. (2000). Health literacy as a public health goal: a challenge for contemporary health education and communication strategies into the 21st century. Health promotion international;15(3):259-67.

- Kickbusch, I., Pelikan, J.M., Apfel, F., Tsouros, A. D., Eds. Health literacy: the solid facts. World Health Organization. Regional Office for Europe. 2013. Erişim Adresi: https://www.euro.who.int/data/assets/ pdf_file/0008/190655/e96854.pdf (Son Erişim Tarihi:15.11.2020)

- Sezgin, D. (2014). Sağlık Okuryazarlığını Anlamak. Galatasaray Üniversitesi İletişim Dergisi, 73-92. Erişim Adresi: http://iletisimdergisi.gsu.edu.tr/tr/pub/issue/7383/96659 (Son Erişim Tarihi:16.11.2020)

- Ad Hoc Committee on Health Literacy for the Council on Scientific Affairs, American Medical Association Health Literacy Report of the Council on Scientific Affairs JAMA 1999; 281(6): 552-557.

- Paakkari, L., \& Okan, O. (2020). COVID-19: health literacy is an underestimated problem. The Lancet. Public health, 5(5), e249-e250. https://doi.org/10.1016/S2468-2667(20)30086-4.

- Tüzün, H, Demirköse, H, Özkan, S, Uğraş Dikmen, A, İlhan, M. (2020). COVID-19 Pandemisi ve Risk İletişimi. Gazi Sağlık Bilimleri Dergisi, 1-8. Erişim Adresi: https://dergipark.org.tr/tr/pub/gsbdergi/ issue/56673/790261 (Son Erişim Tarihi:15.11.2020)

- Eichler, K., Wieser, S., \& Brügger, U. (2009). The costs of limited health literacy: a systematic review. International journal of public health, 54(5), 313-324. Erişim Adresi: https://doi.org/10.1007/s00038009-0058-2 (Son Erişim Tarihi:15.11.2020)

- T.C. Sağlık Bakanlığı COVID-19 Rehberi, Genel Bilgiler, Epidemiyoloji ve Tanı. Erişim Adresi: https:// covid19.saglik.gov.tr/Eklenti/39060/0/covid-19rehberigenelbilgilerepidemiyolojivetanipdf.pdf (Son Erişim Tarihi:15.11.2020)

- Abel, T., \& McQueen, D. (2020). Critical health literacy and the COVID-19 crisis. Health promotion international, daaa040. Advance online publication. Erişim Adresi: https://doi.org/10.1093/heapro/ daaa040 (Son Erişim Tarihi:15.11.2020)

- World Health Organization Novel Coronavirus (2019-nCoV)-Situation Report 13. Erişim Adresi: https:// www.who.int/docs/default-source/coronaviruse/situation-reports/20200202-sitrep-13-ncov-v3.pdf (Son Erişim Tarihi:14.11.2020)

- Rothkopf, D.J., When the Buzz Bites Back. Erişim Adresi: http://www.udel.edu/globalagenda/2004/ student/readings/infodemic.html (Son Erişim Tarihi: 14.11.2020)

- Nielsen, R.K., Fletcher, R., Newman, N., Brennen, J.S., Howard, P.N. (2020). Navigating the 'Infodemic': How People in Six Countries Access and Rate News and Information about Coronavirus Erişim Adresi: https://reutersinstitute.politics.ox.ac.uk/infodemic-how-people-six-countries-access-and-rate-newsand-information-about-coronavirus (Son Erişim Tarihi:15.11.2020) 